\title{
GEOLOGIA DE SUPERFÍCIE E ASPECTOS ESTRUTURAIS DA REGIÃO DE RIO TINTO, FAIXA COSTEIRA DA BACIA DA PARAÍBA
}

Germano Mário Silva Ramos ${ }^{1}$

Osvaldo José Correia Filho ${ }^{1}$

Flávia Araújo de Arruda Cabral ${ }^{2}$

Ewerton Rafael Felipe Bertoldo

Carlos Eduardo Guedes Silva de Oliveira Fabin²

Virgínio Henrique de Miranda Lopes Neumann²

\subsection{0/1980-8208/estudosgeologicos.v31n1p44-68}

1 GEOQUANTT Pesquisa em Geociências, Departamento de Geologia, Universidade Federal de Pernambuco, germanomario.ufpe@gmail.com; osv.correia@yahoo.com.br

2 Departamento de Geologia, Universidade Federal de Pernambuco, neumann@ufpe.br; $\quad$ tonrafael@gmail.com; $\quad$ c.e.fabin@hotmail.com; flavia_araujo7@hotmail.com;

\section{RESUMO}

Este trabalho apresenta o mapeamento geológico na escala 1:50.000, da região de Rio Tinto, que está localizada na faixa costeira da Bacia da Paraíba, Sub-bacia Miriri. O estudo foi realizado com o apoio de interpretação de imagens de satélite, perfis litológicos de poços, análise de lâminas petrográficas e de padrões geomorfológicos. O embasamento aflora em aproximadamente $10 \%$ da área de estudo e é representado por granitóides neoproterozóicos. Cerca de $90 \%$ da área é coberta por depósitos Miocênicos-Pleistocênicos e Quaternários das unidades Barreiras, PósBarreiras e depósitos litorâneos, de Mangue, terraços Pleistocênicos e sedimentos Elúvio-Coluviais. A análise dos dados cartográficos e de imagens de radar mostrou que a região possui um relevo dominado por tabuleiros e vales formados pela reativação Quaternária do arcabouço estrutural da faixa costeira da bacia. O Rio Mamanguape está inserido na falha homônima com direção ENE-WSW, e a drenagem secundária está encaixada em falhas que possuem direções ENE-WSW, NW-SE e N-S. Os dados dos perfis de poços evidenciaram a ocorrência de grabens e horsts formados pela estruturação tardia da faixa costeira da bacia.

Palavras-Chave: Bacia Paraíba; Neotectônica; Margem leste da Província Borborema, Depósitos Quaternários.

\section{ABSTRACT}

This work presents a geological 1:50.000 mapping survey for the Rio Tinto region, located in the coastal zone of Paraíba Basin, Miriri Sub-bacia. The mapping was supported by interpretation of satellite imagery, analysis of well lithologs, thin sections, and morphometric patterns. Basement rocks outcrops in approximately $10 \%$ of the study area, represented by Neoproterozoic granitoids. About $90 \%$ of the region is covered by Miocene-Pleistocene deposits and Quaternary sediments of the Barreiras, post-Barreiras formations, and coastal sandy and mangrove sediments, Pleistocene terraces, and Holocene eluvial-colluvial sediments. Analysis of cartography data and radar images showed that the relief is dominated by small plateaus and valleys formed by the Quaternary erosion of Barreiras Formation 
deposits, controlled by reactivation of the structural framework of the coastal zone. The Mamanguape River follows the homonymous fault, which trends ENE-WSW. The secondary drainage is also controlled by faults trending ENE-WSW, NW-SE, and NS. Correlation of lithologs showed the occurrence of grabens and horsts formed during the late structural evolution of the coastal zone of the basin.

Keywords: Paraíba Basin; Neotectonics, East margin of Borborema Province, Quaternary deposits.

\section{INTRODUÇÃO}

A faixa costeira da Bacia Paraíba é limitada ao sul pela Zona de Cisalhamento de Pernambuco, próximo à cidade de Recife, se estendendo até o alto estrutural de Mamanguape, ao norte da cidade de João Pessoa, na porção oriental do Nordeste brasileiro (Fig. 1). Esta região ainda apresenta uma lacuna em termos de conhecimentos geológicos, quando comparada com as bacias vizinhas, a Bacia Potiguar, a norte, ou a Bacia Alagoas, a sul (Correia Filho, 2015). A coluna sedimentar da faixa costeira da Bacia Paraíba é composta por estratos basais de possível idade Turoniano?Santoniano (arenitos aluviais-fluviais), depósitos transicionais, de idade Campaniana (arenitos calcíferos e calcários com siliciclastos), depósitos calcários de plataforma rasa de idade Maastrichtiano e Paleoceno (calcários e margas), depósitos continentais de idade Mioceno-Pleistoceno (depósitos continentais aluviais e fluviais), e coberturas quaternárias (Beurlen, 1967a; Barbosa et al., 2007). A cobertura sedimentar nesta faixa costeira apresenta pouca espessura, que alcança um máximo de cerca de $400 \mathrm{~m}$ na região do Graben de Itamaracá (Barbosa \& Lima Filho, 2006; Barbosa et al., 2007). A faixa costeira da Bacia da Paraíba está posicionada sobre uma região de elevação do embasamento que se estende desde seu limite sul, até a região do Alto de Touros, a norte da cidade de Natal. Esta faixa se comporta como um alto estrutural alongado, posicionado paralelo à quebra da plataforma (Barbosa e Lima Filho, 2006; Buarque et al., 2016).

A região de estudo apresenta poucos trabalhos realizados em escala de detalhe sobre os aspectos de geologia de superfície e de subsuperfície. A região apresenta alguns aspectos relacionados à exploração de recursos econômicos como areia para a construção civil e calcário por parte da indústria cimenteira, e por isto a ampliação do conhecimento da área é importante (Neumann \& Guerra, 2014; Santos \& Ferreira, 2002).

O presente trabalho teve como objetivo realizar um levantamento de geologia de superfície na região do município de Rio Tinto localizada na faixa costeira da Bacia da Paraíba, entre as folhas de Cabedelo e Guarabira (1:100.000). O estudo foi realizado por meio do mapeamento sistemático das formações geológicas, guiado pela base cartográfica e geológica existente. Foi realizada a coleta de amostras e a interpretação de características petrográficas de alguns depósitos. Também foi realizada uma integração de dados de superfície com dados de subsuperfície por meio da análise de perfis litológicos de poços perfurados na região para o aproveitamento de recursos hídricos. Os dados obtidos permitiram detalhar as informações dos mapas geológicos existentes para essa região com a confecção de mapas na escala de 1:50.000, bem como evidenciar 
aspectos importantes sobre o controle de processos neotectônicos na configuração morfológica da área.

\section{LOCALIZAÇÃO}

A área de estudo está situada na região costeira do Estado da Paraíba (Fig. 1), entre as cidades de Cabedelo e Barra de Mamanguape. Estes municípios estão localizados próximos ao flanco norte da Bacia
Paraíba e estes também ficam aproximadamente a $16 \mathrm{~km}$ da capital do estado da Paraíba, João Pessoa. O polígono da área estudada é representado pelas seguintes coordenadas, UTM E: 263000 e 268600, UTM N: 925500 e 922400. Para a elaboração dos mapas e perfis, o sistema de projeção foi integrado para o datum WGS84. O acesso para a área de estudo pode ser feito por meio da BR-101 e pela BR-230.

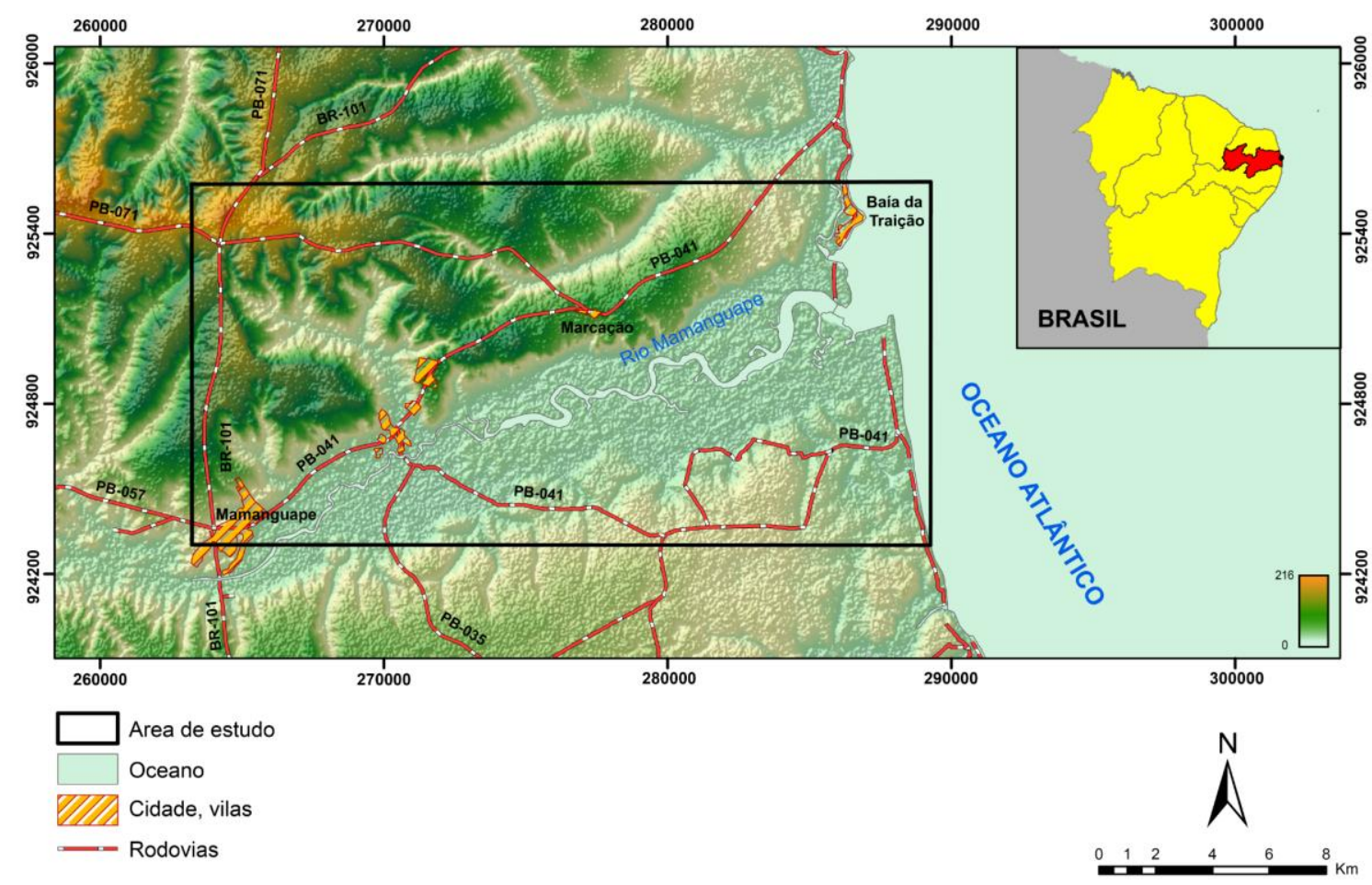

Figura 1 - Mapa de localização da área de estudo com as principais vias de acesso, confeccionado sobre um modelo digital de elevação construído a partir de imagens de radar. A área de mapeamento é compreendida pelo retângulo em preto, e está localizada na região norte do Estado da Paraíba (detalhe no alto à direita), a norte da capital João Pessoa.

\section{MATERIAIS E MÉTODOS}

Além da pesquisa bibliográfica, foi realizado levantamento de imagens de satélite do acervo do Google Earth Pro, e de imagens de radar com resolução espacial de 100 m (SRTM - Shuttle Radar Topography Mission). Foram utilizados também mapas geológicos da folha Guarabira e Cabedelo, ambos fornecidos pelo GEOBANK do Serviço
Geológico do Brasil CPRM. Através da análise das imagens de radar foi possível realizar a interpretação dos principais lineamentos topográficos através do método de iluminação para realce das feições morfológicas, e identificação de curvas de nível em intervalos de 10 metros para auxiliar a identificação dos contatos geológicos entre as formações e litotipos. 
Para execução do trabalho de mapeamento foram utilizadas bússolas, escalas gráficas, ácido clorídrico $(\mathrm{HCl})$ em solução de $10 \%$, registro fotográfico, lupas, caderneta de campo, martelo, marreta, e GPS. Foram realizadas 146 estações de definição dos aspectos geológicos com um espaçamento de aproximadamente 1 $\mathrm{km}$ entre cada ponto. Foram realizadas análises de classificação macroscópica dos depósitos a partir de amostras de mão, descrição de seções delgadas e uma classificação estatística das características texturais do material de natureza clástica coletado com o uso de lupa monocular Dino-Lite AM4815ZT. O estudo também utilizou as informações de três perfis litológicos de poços perfurados na região que foram adquiridos a partir do Sistema de Informações de Águas Subterrâneas (SIAGAS - CPRM). Estes perfis foram utilizados para a verificação da espessura das unidades, posicionamento do embasamento e interpretação de aspectos estruturais, e correlação de unidades estratigráficas.

\section{CONTEXTO GEOLÓGICO}

A Bacia Paraíba está localizada na margem leste da província estrutural da Borborema (PB), e faz limite a sul, por meio da Zona de Cisalhamento de Pernambuco, com a Bacia de Pernambuco (Mabesoone \& Alheiros, 1988, 1993; Barbosa et al., 2007; Correia Filho et al., 2019). Esta região representa, possivelmente, uma etapa tardia de evolução do Oceano Atlântico Sul Central, a partir do processo de propagação do rifte Cretácico (Fig. 2) (Matos, 1999, Matos et al., 2021; Barbosa e Lima Filho, 2006; Buarque et al., 2016). A faixa costeira das bacias que formam a margem leste da PB é estreita, assim como a zona de plataforma destas bacias. Este trecho da margem continental apresenta embasamento elevado que constitui um alto estrutural (Barbosa et al., 2007; Magalhães et al., 2013; Buarque et al., 2016; Matos et al., 2021). A espessura sedimentar na faixa costeira da Bacia Paraíba alcança valores máximos sobre os grabens de Miriri e Alhandra em torno de $250 \mathrm{~m}$, e sobre o Graben de Itamaracá alcança cerca de de 400 m (Barbosa \& Lima Filho, 2006; Barbosa et al., 2007). A evolução da bacia foi fortemente controlada pelas zonas de cisalhamento do embasamento Pré-Cambriano com direções principais NE-SW, ENEWSW, e E-W. Essas estruturas foram reativadas durante 0 rifte Cretácico como falhas normais e oblíquas (Lima et al., 2016; Correia Filho et al., 2019). Este processo controlou a compartimentação da bacia em faixas com orientação E-W e ENE-WSW. O processo de distensão aproximada E$W$ do rifte também criou falhas de transferência com direção NW-SE, e falhas normais com direção N-S e NNW-SSE (Barbosa \& Lima Filho, 2006; Bezerra et al., 2014; Correia Filho et al., 2019). Até o Albiano o alto estrutural que bordeja as bacias da Paraíba e Plataforma de Natal permaneceu elevado com o offset da sedimentação para a parte distal do rifte nesta área, o que resultou na ausência de depósitos desta idade na faixa costeira destas (Fig. 2) (Barbosa et al., 2007; Magalhães et al., 2013; Buarque et al., 2016; Matos et al., 2021). Embora a idade do break-up nesta região ainda seja motivo de debate, alguns autores têm sugerido que esta separação teria ocorrido no 
Albiano Inferior (Matos, 1999; Caixeta et al., 2015; Buarque et al., 2016).

Evidências demonstraram que estas bacias da margem leste da PB, bem como a Bacia Potiguar, tem passado por um regime de reativação que provavelmente se iniciou desde o final do Cretáceo, e que apresenta um regime transcorrente com direção aproximada E-W (Bezerra et al., 2014, 2020; Lima et al., 2016; Correia Filho et al., 2019). Este processo, associado a variações climáticas e eustáticas controlou a formação do relevo nas bacias deste trecho da margem, em especial a Bacia da Paraíba (Bezerra et al., 2014; Lima et al., 2016). A reativação provocou 0 rejuvenescimento dos vales dos rios e a erosão dos depósitos das unidades sedimentares (Lima et al., 2016; Rossetti et al., 2013).

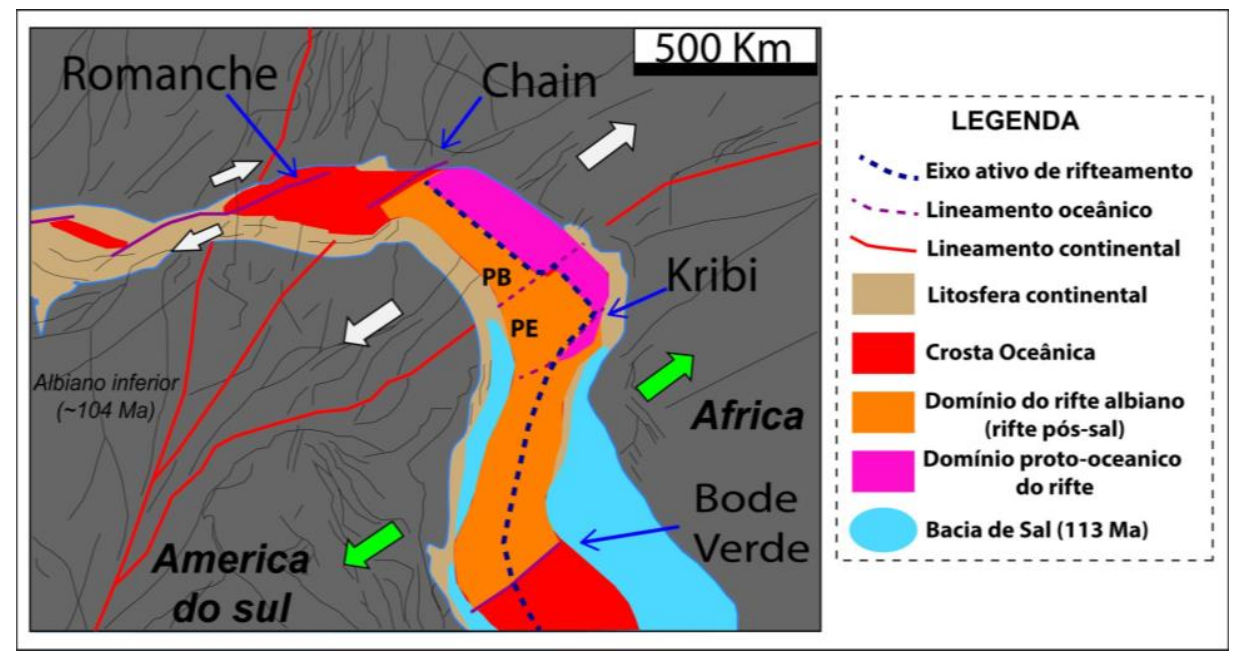

Figura 2 - Paleomapa com a reconstrução do rifte Atlântico Sul-Equatorial Durante Aptiano (Adaptado de Matos et al. 2021). A faixa de embasamento referente à plataforma continental das bacias da Paraíba e da Plataforma de Natal permaneceu elevada, o que resultou na ausência de depósitos do Aptiano e Albiano. Setas verdes - distensão oblíqua ao eixo do rifte, setas brancas maiores - distensão perpendicular, setas brancas menores - regime transcorrente.

A Bacia da Paraíba está localizada sobre o bloco central da PB, a Zona Transversal, (Delgado et al., 2003; Andrades-Filho et al., 2014; Correia Filho et al., 2015), mais especificamente nos domínios Alto Pajeú, Alto Moxotó e Rio Capibaribe. A Coluna sedimentar da atual faixa costeira da Bacia da Paraíba é constituída da seguinte forma (Fig. 3): 1 - a unidade basal representada pela
Formação Beberibe, que é composta por arenitos continentais médios a grossos, com níveis conglomeráticos formados em sistemas aluviais e flúvio lacustres (Kegel, 1955; Beurlen, 1967a; Mabesoone \& Alheiros, 1988); 2 - a segunda unidade formada em ambiente transicional a marinho restrito, Formação Itamaracá, de idade Campaniano, que é composta por margas, calcários com siliciclastos, 
arenitos calcíferos e dolomitos, formados em sistemas costeiros estuarinos e lagunares (Kegel, 1955; Muniz, 1995; Barbosa et al., 2007); a terceira unidade representada pela Formação Gramame, Maastrichtiano, depositada em ambiente marinho batial e composta por camadas de margas e calcários margosos ricamente fossilíferos (Beurlen, 1967a; Mabesoone \& Alheiros, 1988; Muniz, 1993; Fauth \& Koutsoukos, 2002; Barbosa et al., 2007); a quarta unidade é composta por camadas de calcários margosos, margas e calcários com siliciclastos da Formação Maria Farinha, Paleoceno, que foram depositadas em sistemas plataformais rasos, estuários e lagunas (Beurlen, 1967a; Barbosa et al., 2007), a quinta unidade é representada pelos depósitos da Formação Tambaba, Eoceno, que é composta por camadas de calcários bioclásticos, dolomitos e calcários margosos, depositados em sistemas recifais, lagunar e costeiro também ricamente fossilíferas (Beurlen, 1967a; Barbosa et al., 2006; Correia Filho et al., 2015; Távora et al., 2017) (Fig. 3).

As unidades carbonáticas representam um ciclo transgressivoregressivo que alcançou a faixa costeira da bacia e formou uma plataforma carbonática rasa e influenciada por siliciclásticos sobre 0 alto estrutural que a configura. Estas unidades foram fortemente afetadas por processos erosivos que se desenvolveram na faixa costeira devido a condicionantes estruturais climáticos e eustáticos. A Formação Gramame ocorre em praticamente toda a faixa costeira da Bacia Paraíba, a Formação Maria Farinha ocorre no setor sul da bacia entre as cidades de Recife e a região da llha de Itamaracá. A Formação Tambaba ocorre na linha de litoral ao sul da cidade de João Pessoa, em uma faixa de cerca de $6 \mathrm{~km}$ (Correia Filho et al., 2015; Távora et al., 2017).

Sobre os depósitos da Formação Maria Farinha foram depositados discordantemente os sedimentos da Formação Barreiras, MiocenoPleistoceno, que é composta por sedimentos continentais arenoargilosos de sistemas aluviais, fluviais e litorâneos (Mabesoone \& Alheiros, 1988; Barbosa et al., 2007; Rossetti et. al., 2013). Acima da Formação Barreiras ocorrem sedimentos quaternários, também denominados de sedimentos Pós-Barreiras, que representam 0 produto de erosão controlada por processos eustáticos e climáticos ocorridos durante 0 Holoceno (Rossetti et al., 2011) (Fig. 3). Terraços arenosos holocênicos e pleistocênicos formados por paleopraias posicionadas acima do nível do mar atual também ocorrem na faixa costeira. Além disso, existem sedimentos holocênicos formados pelos sistemas atuais, sedimentos arenosos aluvionais, mangues, terraços e material de colúvio que recobre parte dos tabuleiros costeiros, encostas e vales de rios (Fig. 4). 


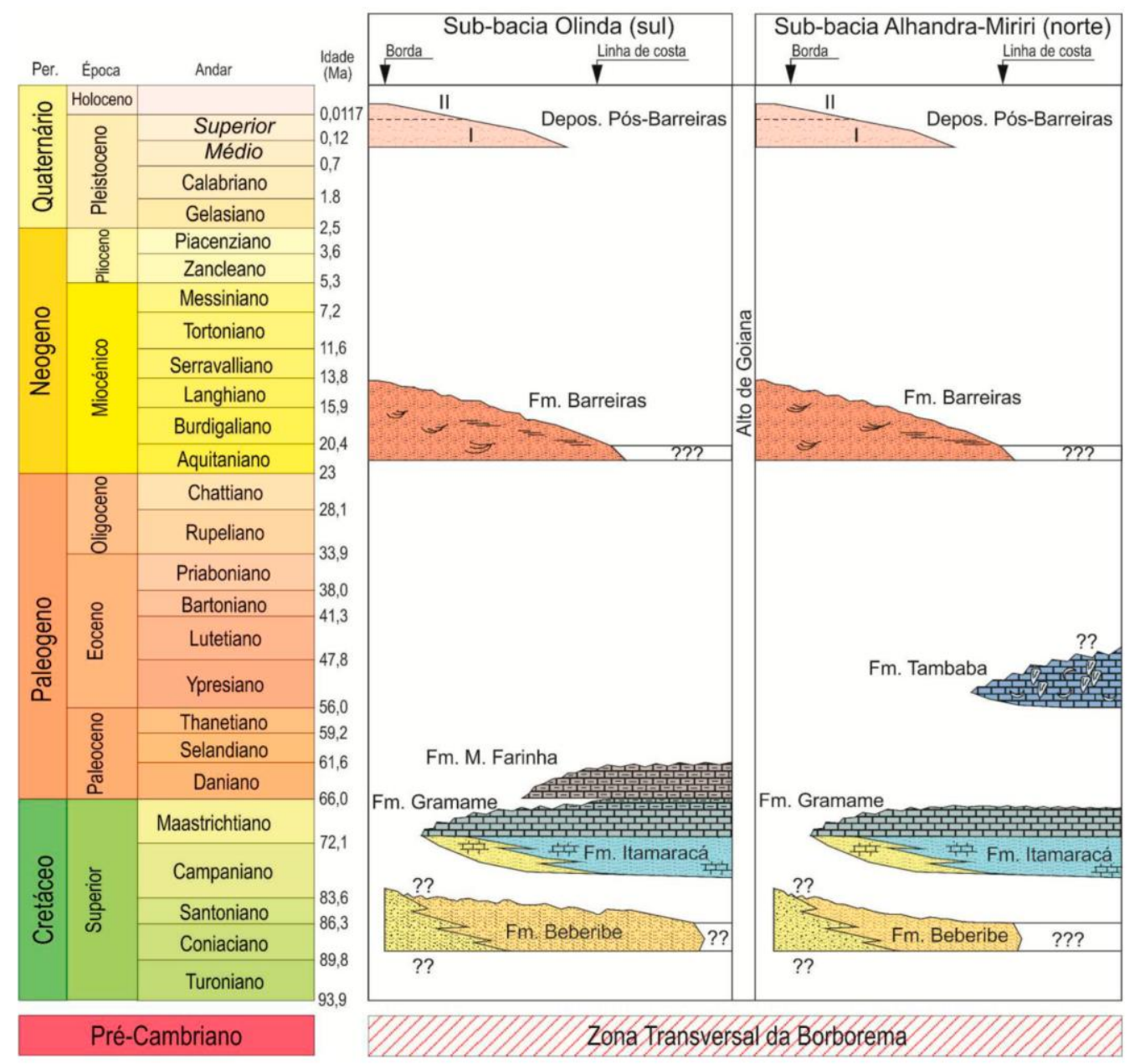

Figura 3 - Carta estratigráfica da faixa costeira da Bacia Paraíba, com o efeito da distribuição das formações nas sub-bacias de Olinda e de Alhandra-Miriri (a partir de Correia Filho et al., 2015).

\section{RESULTADOS}

A realização do levantamento geológico de superfície possibilitou a identificação de depósitos de duas unidades estratigráficas: Formação Barreiras e sedimentos Pós-Barreiras, além de coberturas sedimentares quaternárias (Terraços arenosos pleistocênicos, sedimentos aluvionares, sedimentos de manguezais, sedimentos litorâneos arenosos, sedimentos colúvio-eluviais relacionados às encostas de tabuleiros costeiros. Os depósitos sedimentares recobrem cerca de $90 \%$ da área estudada. Cerca de $70 \%$ da cobertura sedimentar é composta por sedimentos colúvio-eluviais. Os demais $10 \%$ da área apresentam exposições de rochas do embasamento da Suíte Intrusiva Ouro Branco (Fig. 4). 


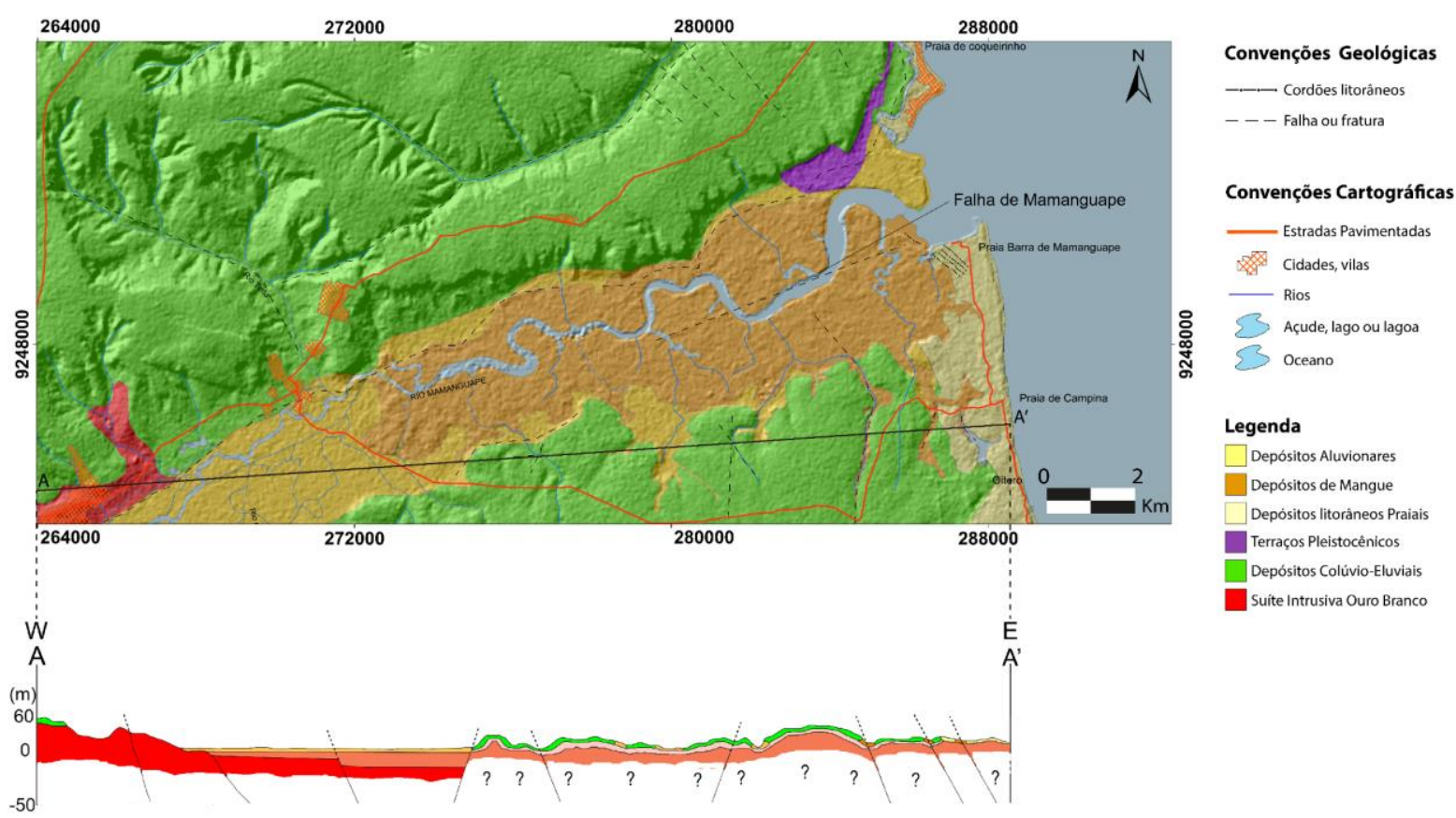

Figura 4 - Mapa geológico da região estudada com a distribuição das unidades estratigráficas e litotipos. O perfil A-A' localizado de forma longitudinal, na porção sul da área de estudo, mostra a interpretação do comportamento das unidades estratigráficas e do embasamento. A interpretação das falhas e do comportamento do embasamento foi realizada com base no processamento das imagens de radar, e em estudos anteriores realizados na faixa costeira (Barbosa \& Lima Filho, 2006; Barbosa et al, 2007; Lima et al., 2016) (Escala 1:50.000).

\section{Embasamento}

As rochas do embasamento continental, que afloram na porção oeste da área, pertencem à Suíte Intrusiva Ouro Branco. Estas afloram na periferia da cidade de Mamanguape (Fig. 5A), borda da bacia. A pesquisa acessou estas rochas em afloramentos naturais e em pedreiras, o que auxiliou sua caracterização. As rochas apresentam textura equigranular a levemente porfiritica, com granulação que varia de fina a média. Não foi observada uma orientação mineralógica sistemática. Nestas rochas ocorrem veios de quartzo com direção NE-SW. A análise petrográfica (Fig. 5B) revelou a presença de quartzo, feldspato, microclina, muscovita, plagioclásio, hornblenda, biotita e zircão. A distribuição de quartzo, feldspato e plagioclásio no diagrama QAP (Streckeisen, 1976), permitiu a classificação das rochas como sienogranito e monzogranito. Observou-se a presença de textura mimerquítica e textura porfirítica, caracterizada pela presença de fenocristais de plagioclásio e microclina. A presença de muscovita sugere que estas rochas apresentam alto teor de alumina, o que permite considerá-las como de afinidade peraluminosa.

\section{Cobertura sedimentar}

Os depósitos colúvio-eluviais recobrem a maior parte da área. Estes, possivelmente, representam um produto do intemperismo dos depósitos da Formação Barreiras (Correia Filho, 2015) na etapa mais recente de erosão destes depósitos. Estes sedimentos também recobrem depósitos da 
unidade Pós-Barreiras (Rossetti, et al. 2011), cuja espessura pode chegar a até 15 metros. A Formação Barreiras aflora apenas nas falésias junto à linha de litoral. Os Terraços Pleistocênicos se encontram um pouco mais afastados da costa com uma cota média de 15 metros em relação ao nível do mar. Estes terraços podem ser produto da penúltima transgressão marinha que ocorreu durante o Pleistoceno, há 120.000 anos.

Os depósitos litorâneos praiais estão localizados na linha de costa e são produtos da construção do litoral nesta região desde a última transgressão do Holoceno. Estes sedimentos de cordões litorâneos e dunas apresentam composição quartzosa com variado grau de contribuição carbonática bioclástica. Também foram mapeados sedimentos de aluviões recentes e sedimentos de mangue, argila e areia, associados a rede de drenagem que existe na área. Devido ao efeito de afogamento dos estuários causado pela última transgressão, a ação das marés é importante nos grandes rios da região, o que influencia a formação de depósitos de mangue e planícies de maré (Alves, 2016; Alves \& Rossetti, 2016).

\section{Formação Barreiras}

Na área de estudo, a Formação Barreiras foi encontrada somente em falésias ao longo da linha de costa (Fig. $5 \mathrm{C})$, mais especificamente entre as praias de Campina e Barra de Mamanguape. Os depósitos desta unidade apresentam granulação de média a grossa com níveis conglomeráticos (Fig. 5D), e coloração avermelhada, sugerindo que a formação foi depositada em ambiente de elevada oxidação. Também ocorrem níveis argilosos de coloração variada. Alheiros e Lima Filho (1991) associaram a origem dos depósitos da Formação Barreiras que ocorrem na faixa costeira entre Recife e João Pessoa a sistemas fluviais entrelaçados, sistemas de leques aluviais e litorâneos. Estes autores propuseram que na região de Rio Tinto ocorre o predomínio de depósitos de fácies fluviais. Esta unidade foi fortemente afetada pelo processo de dissecação influenciado por efeitos climáticos e eustáticos no Holoceno, incluindo processos de Neotectônica que produziram deformação sinsedimentar e o rejuvenescimento de vales fluviais (Furrier et al.,2006; Bezerra et al., 2014; Araújo et al., 2006; Lima, 2010)

\section{Sedimentos pós-barreiras}

Os sedimentos Pós-Barreiras
foram encontrados em poucos
afloramentos na porção nordeste da
área de estudo, e estes são
caracterizados pela presença de crosta
laterítica (Fig. 5E) em contato com
arenitos friáveis de coloração creme.
Entretanto, nesta área grande parte
desses sedimentos foram capeados
pelos depósitos colúvio-eluviais, o que
torna difícil sua identificação e sua
diferenciação em relação às litologias
sobrejacentes. Localmente, ocorrem
blocos lateríticos rolados (Fig. 5F), que
possivelmente representam retrabalha-
mento dos sedimentos Pós-Barreiras.



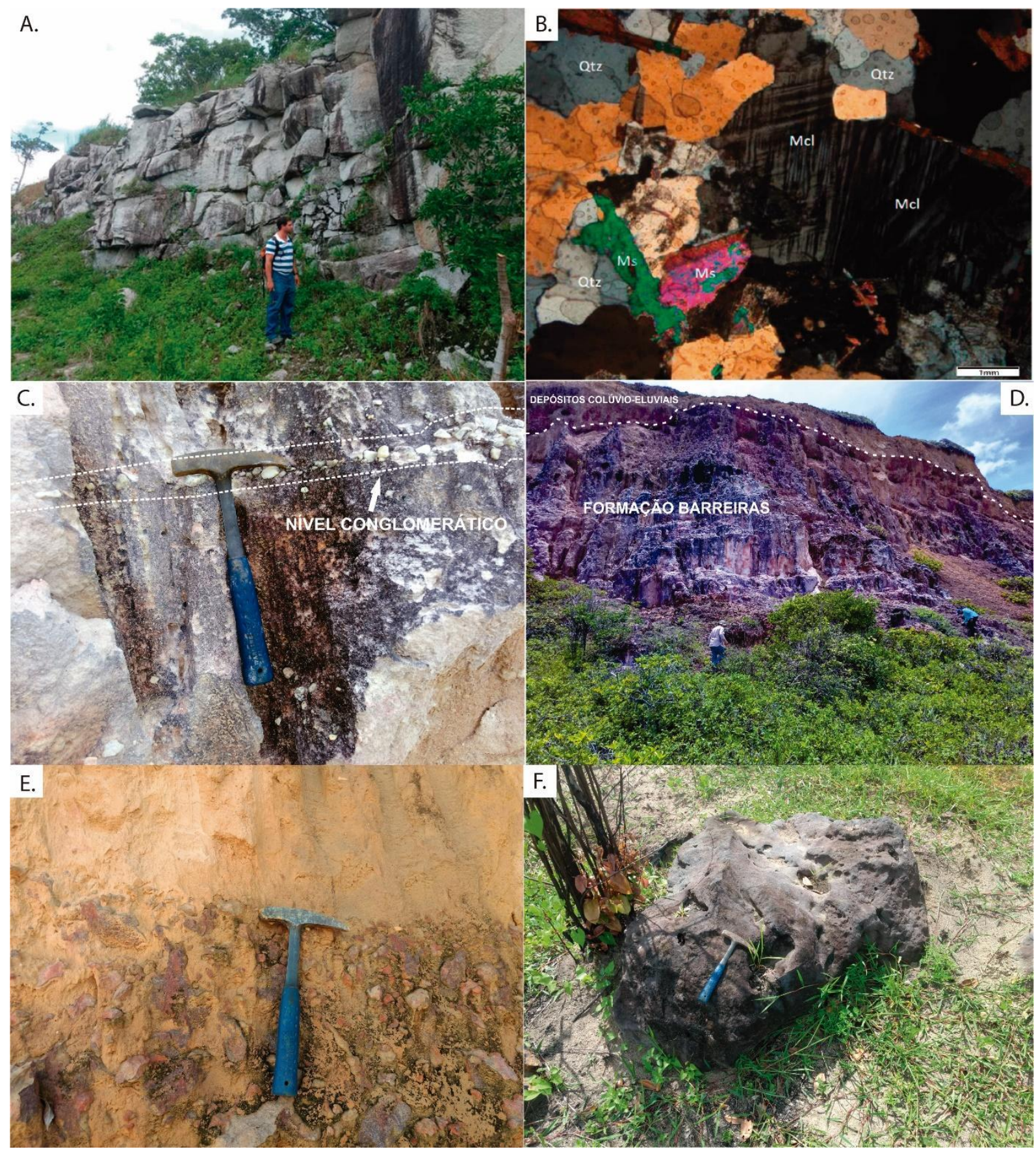

Figura 5 - A) Afloramento da Suíte Intrusiva Ouro Branco em uma pedreira desativada na cidade de Mamanguape. As rochas apresentavam estruturas sub-horizontais como resposta ao alívio de pressão, e apresentam variado grau de erosão. B) Micrografia de lâmina delgada da rocha encontrada neste local com aumento 4x (Qtz - Quartzo, $\mathrm{Mcl}$ - Microclina, Ms - Muscovita). C) Depósitos da Formação Barreiras recobertos por depósitos colúvio-eluviais em uma falésia localizada na Praia de Barra de Mamanguape (Fig. 01). D) Afloramento da Formação Barreiras com níveis conglomeráticos (linha tracejada) na falésia da Praia de Barra de Mamanguape. E) Sedimentos Pós-Barreiras em contato com camada de sedimentos retrabalhados caracterizados pela presença de óxido de ferro (laterita). F) Bloco de arenito cimentado com óxido de ferro formado a partir de retrabalhamento de sedimentos da unidade Barreiras, próximo a cidade de Marcação, PB. 
Terraços pleistocênicos

Exemplos de terraços marinhos pleistocênicos foram mapeados a cerca de $1,5 \mathrm{~km}$ da Praia de Coqueirinho, a aproximadamente 1,5 metros acima do atual nível relativo do mar. Estes depósitos de antigas praias do Quaternário são dominantemente compostos por areia quartzosa de coloração branca a cinza e possuem alguns metros de espessura (Figs. 6A e 6B) (Suguio, 2017). Os depósitos de terraços apresentam coloração escura em subsuperfície. Este fato pode indicar a impregnação de ácido húmico e/ou fúlvico a partir da percolação de água em solos ricos em matéria orgânica (Suguio et al., 2005). Estes depósitos formam manchas distribuídas pela faixa costeira a partir da formação de antigas praias durante a transgressão marinha ocorrida há aproximadamente 120.000 anos.

\section{Depósitos colúvio-eluviais}

Os depósitos colúvio-eluviais afloram em praticamente $70 \%$ da área estudada e são formados por sedimentos inconsolidados, de coloração marrom, amarelada ou esbranquiçada (Fig. 6C). Estes representam 0 lixiviamento das unidades Barreiras e Pós-Barreiras com pouco transporte sobre os tabuleiros (Neumann \& Guerra, 2014), e com uma maior ação da gravidade como agente de transporte nas encostas das estruturas dissecadas pela erosão. Além disso, infere-se que o intemperismo químico de rochas desagregadas in situ e o transporte eólico tenham apresentado alguma influência na sua formação. Localmente foi verificado, em alguns cortes de estrada, a presença de areia com coloração amarelada, contendo camadas intercaladas de composição cascalhosa,

grãos subarredondados, o que sugere a formação de depósitos de leques aluviais (Fig. 6D). Esses depósitos podem alcançar até 10 metros de espessura. Algumas empresas se instalaram na região para realizar a extração destas areias quartzosas que são utilizadas pela construção civil.

\section{Depósitos praiais}

Os depósitos praiais estão localizados nas proximidades da linha de costa da área de estudo e representam cordões litorâneos e dunas de pequeno porte (Fig. 6E). Estes indicam o efeito das oscilações eustáticas que influenciaram fortemente a formação de depósitos costeiros no Holoceno. A composição destes sedimentos é representada por areia de quartzosa, com pouca contribuição de material carbonático, de coloração esbranquiçada, e sua granulação varia de $0,062-2 \mathrm{~mm}$, areia muito fina, a grânulos, segundo a tabela granulométrica de Wentworth (1922) (Fig. 6F). O arredondamento dos grãos de quartzo varia de subanguloso a anguloso, sugerindo que o material é autóctone. Os sedimentos também apresentam alguns horizontes com ocorrência de conchas de moluscos bem preservados. Além disso, é comum a formação de camadas de coloração escura associada à presença de minerais pesados nas proximidades dos estuários.

\section{Depósitos de mangue}

Os mangues estão associados ao bioma da Mata Atlântica. Estes possuem a função importante de proteger a costa, e atuam na contenção de sedimentos provenientes das bacias hidrográficas, e também representa um habitat para alimentação e procriação de inúmeras espécies marinhas (Alves, 2001). Os sedimentos de mangue 
estão situados principalmente no baixo curso dos rios da área estudada (Fig. $6 G)$, que são influenciados pelas fortes variações das marés. Estes sedimentos apresentam composição dominantemente lamosa, e sua granulação varia de silte a argila, com abundante conteúdo de matéria orgânica devido à alta produtividade associada aos sistemas estuarinos. Os depósitos de mangue apresentam de forma geral relação espacial com outros tipos de estruturas relacionadas à formação de estuários e planícies de maré como barras de desembocadura, cordões arenosos e beachrocks devido à proximidade com os sistemas costeiros. $\mathrm{Na}$ área de estudo, os depósitos de mangue ocorrem em uma área de relevo plano e topografia rebaixada, e alagada pelo processo de oscilação das marés. Este sistema foi mapeado com base no acesso limitado que foi realizado no levantamento de campo e com auxílio dos mapas topográficos e de imagem de satélites, a partir do controle pelas curvas de nível.

\section{Depósitos aluvionares}

Os depósitos de aluviões estão localizados nas margens dos rios (Fig. $6 \mathrm{H})$. Em grande parte, estes estão relacionados à deposição de sedimentos na planície de inundação do Rio Mamanguape e seus afluentes (Fig. 1). Os sedimentos de aluviões são compostos predominantemente por material quartzoso siltoso, de coloração amarronzada. Estes depósitos apresentam também variado conteúdo de matéria orgânica em sua composição devido à proximidade com os depósitos de mangue.

\section{ANÁLISE DOS LINEAMENTOS TOPOGRÁFICOS}

A partir da análise do modelo digital do terreno construído a partir das imagens de radar, foi possível realizar a identificação dos principais lineamentos topográficos que existem na área de estudo. O recurso de variação da iluminação foi aplicado para uma avaliação da consistência do processo de extração automática das informações de lineamentos. Para isso foram aplicados de diferentes ângulos $(45 \mathrm{Az}, 135 \mathrm{Az}, 225 \mathrm{Az}$ e $315 \mathrm{Az})$ com o objetivo de ressaltar 0 efeito de expressão dos lineamentos. Este processo permitiu a identificação da influência do controle subjacente do embasamento no processo de erosão, e dissecação dos depósitos sedimentares potencializados por processos climáticos e eustáticos. A partir da extração automática dos lineamentos, foi realizada a interpretação quantitativa de suas direções e a construção de diagramas de roseta. $O$ processo foi realizado para cada mapa criado pelo efeito de iluminação descrito acima. Além disso, foi construída uma roseta com a compilação de todas as orientações de lineamentos identificados nos mapas de iluminação (Figs. 7 e 8).

Os lineamentos topográficos exibem duas direções preferenciais: L1) NNE-SSW; e L2) NW-SE; e trends secundários com direção E-W e N-S (Fig. 8). As direções desses lineamentos, nos quais a drenagem está encaixada, e que também definem os contornos do padrão de dessecamento dos depósitos quaternários, estão relacionadas ao padrão de zonas de cisalhamento e de falhas do rifte do embasamento subjacente (Bezerra et al., 2014; Correia Filho et al., 2019; AndradesFilho et al., 2021). Esta relação sugere o controle do embasamento no processo de condicionamento da drenagem e da erosão neste trecho da faixa costeira, e reforça os resultados 
obtidos por outros trabalhos que abordaram toda a faixa costeira da bacia (Furrier, et al., 2006; Rossetti et al., 2011; Bezerra et al., 2014).

Contudo, devido à natureza de desgaste das rochas aflorantes (Formação Barreiras e depósitos da unidade Pós-Barreiras), não foi possível executar a coleta de informações detalhadas sobre as atitudes das estruturas nos afloramentos. Os poucos afloramentos com melhor preservação não apresentam, por exemplo, feições como estrias nos planos de falhas que podem ser observados em alguns locais.

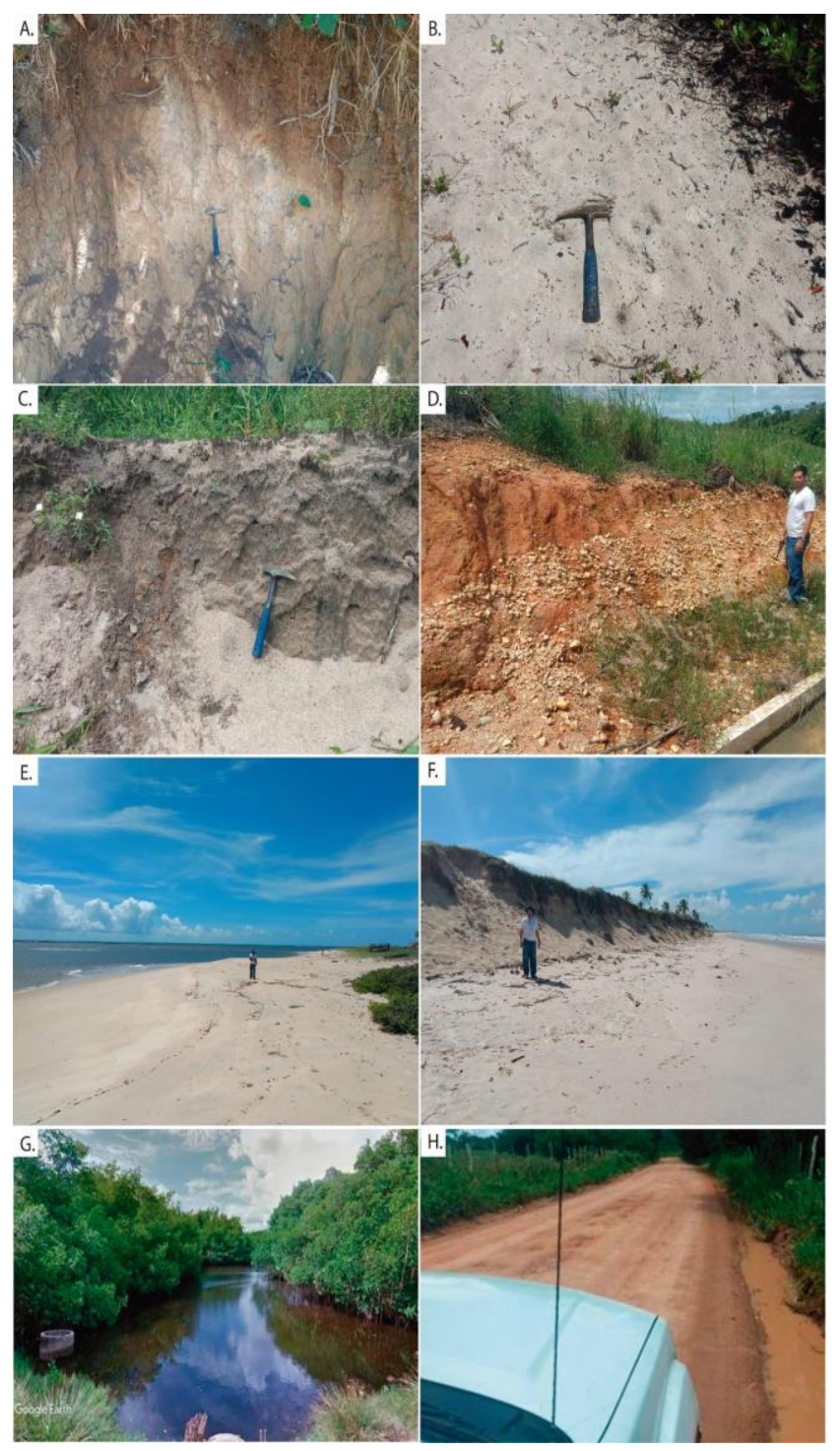

Figura 6 - Características dos sedimentos quaternários e holocênicos encontrados na região. A e B) sedimentos de terraço Pleistocênico, C) Sedimento arenoso colúvioeluviais de coloração esbranquiçada, muito usado na fabricação de vidro devido ao seu alto teor de quartzo. D) Depósitos aluviais com níveis cascalhosos. E) Sedimentos de praia com formação de pequenas dunas, F) Erosão de sedimentos de praia na Praia de Coqueirinho do Norte. G) Área alagada de manguezal, com domínio de sedimentos lamosos, na localidade de Praia de Campina (Fonte: Google Earth). H) Sedimentos de aluvião em corte de estrada com coloração vermelho-marrom, próximo a cidade de Rio Tinto. 

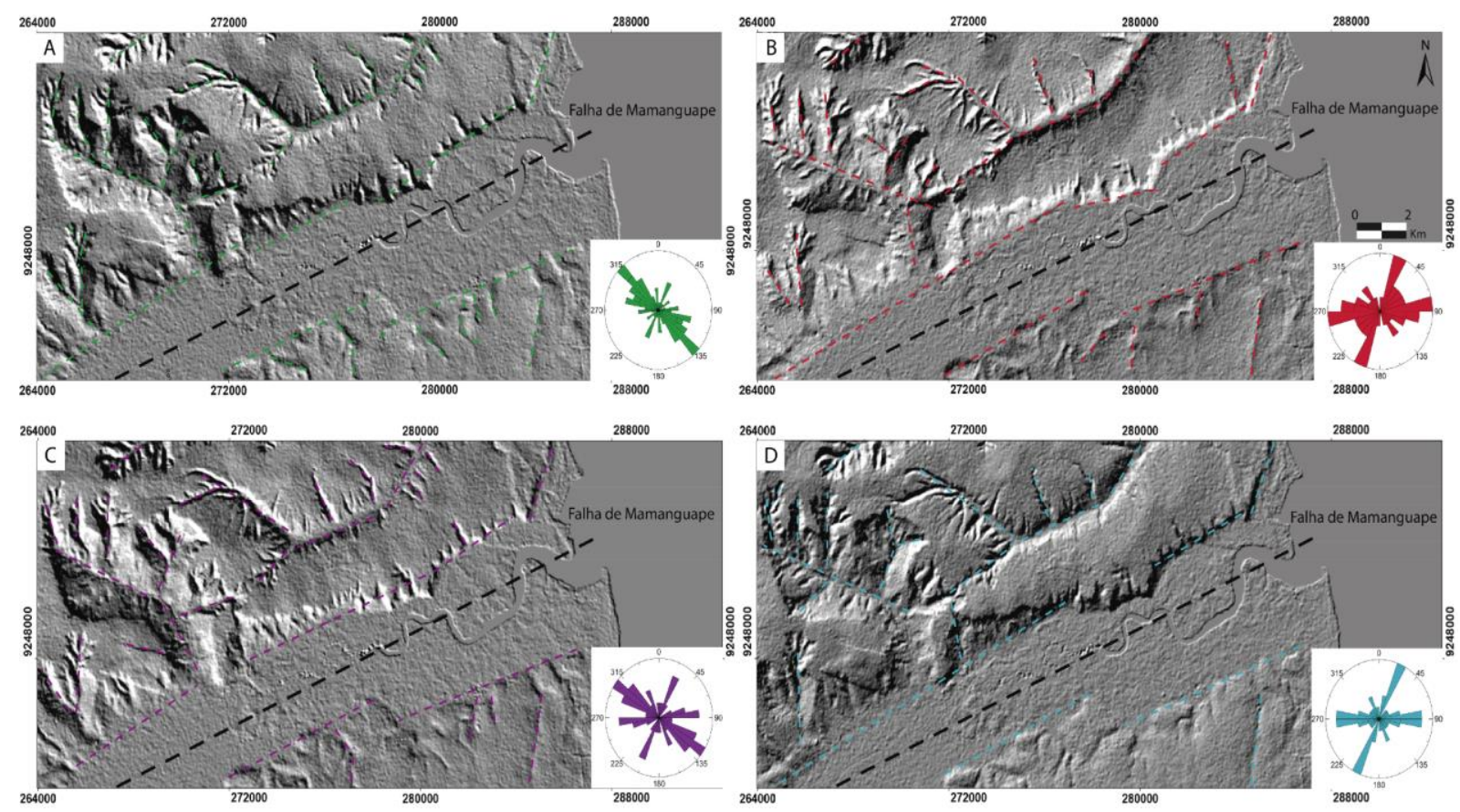

Figura 7 - Modelo de elevação do terreno com quatro direções de iluminação utilizados para a extração de lineamentos topográficos. Direção de iluminação: A) 45 Az, B) 135 Az, C) $225 \mathrm{Az}$ e D) $315 \mathrm{Az}$. Os principais lineamentos também foram interpretados sobre cada mapa criado a partir do controle de iluminação (linhas coloridas tracejadas). A linha tracejada preta indica a inferência da zona de falha de Mamanguape. Os diagramas de rosetas mostram o resultado da extração automática de lineamentos em cada mapa.

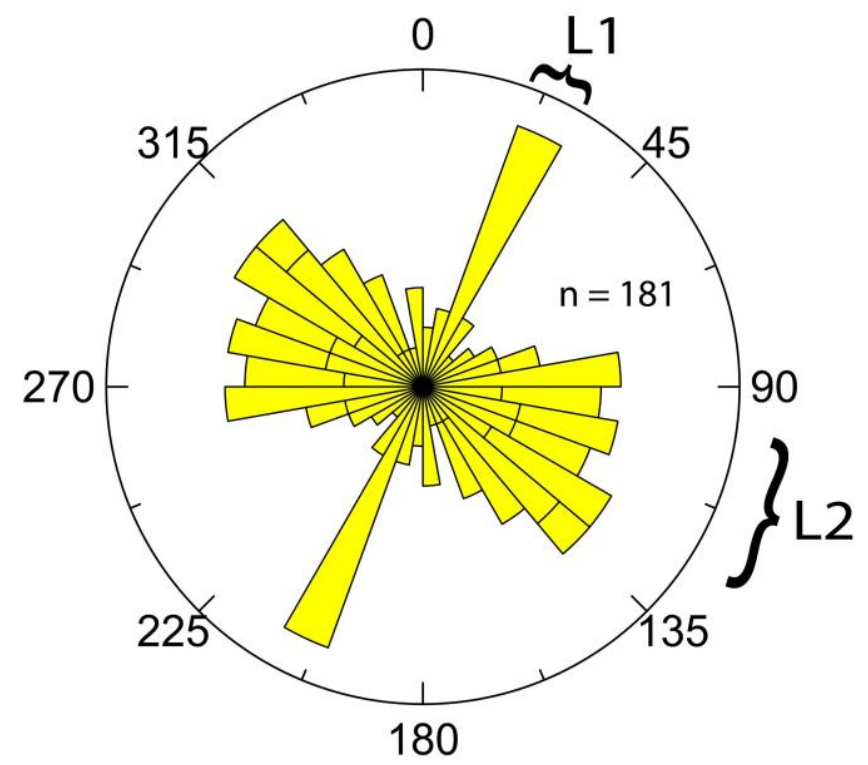

Figura 8 - Diagrama de roseta com a sobreposição de todos os lineamentos extraídos nas imagens do modelo digital de terreno com diferentes orientações de iluminação (Fig. 7). 


\section{PERFIS LITOLÓGICOS DE POÇOS E A GEOLOGIA DE SUPERFÍCIE}

A correlação dos perfis litológicos de alguns poços executados na região permitiu estabelecer uma integração entre a geologia de superfície e características do arcabouço tectono-estratigráfico (Figs. 9 e 10). Em especial foi possível definir a profundidade do embasamento em alguns locais e reforçar a interpretação sobre a posição de falhas do embasamento cuja expressão controla a orientação da drenagem e o processo de modelagem do relevo (Figs. 9 e 10). O embasamento raso foi alcançado nos perfis dos poços Salemas, posicionado dentro do vale do Rio Mamanguape, e Pilõezinhos, localizado a NE sobre o horst do embasamento (Fig. 10). Estes poços estão afastados cerca de $600 \mathrm{~m}$

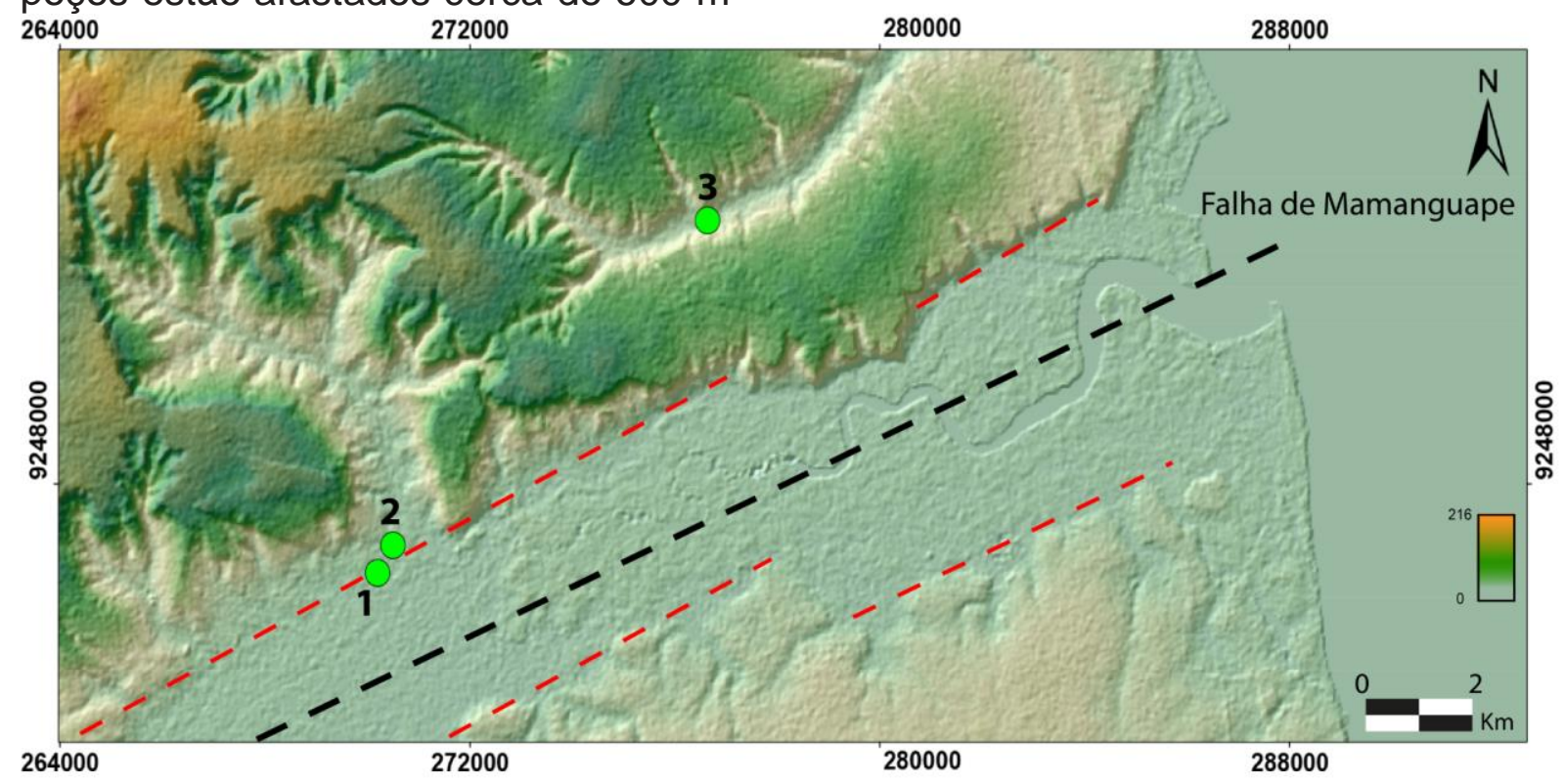

entre si, e a cota do topo do embasamento entre eles apresenta uma diferença de $4 \mathrm{~m}$. Isto revela a magnitude de rejeito de pequeno porte na estruturação do embasamento nesta porção mais proximal da faixa costeira. Além disso, estes dados sobre a cobertura sedimentar sugerem que as formações carbonáticas do Cretáceo não estão presentes, e que possivelmente ocorrem apenas depósitos da unidade basal da Formação Itamaracá, ou Beberibe, e da unidade Barreiras, além de sedimentos retrabalhados na porção superficial do perfil (Fig. 10).

Figura 9 - Localização dos poços utilizados para a investigação da cobertura sedimentar em subsuperfície. Os perfis litoestratigráficos foram comparados para um melhor entendimento do controle exercido pelo embasamento entre a região rebaixada do vale do Rio Mamanguape e a região elevada com tabuleiros a norte. A linha tracejada vermelha indica a interpretação de falhas nos limites do atual vale fluvial. A linha tracejada preta indica a posição inferida da zona de falha de Mamanguape. 


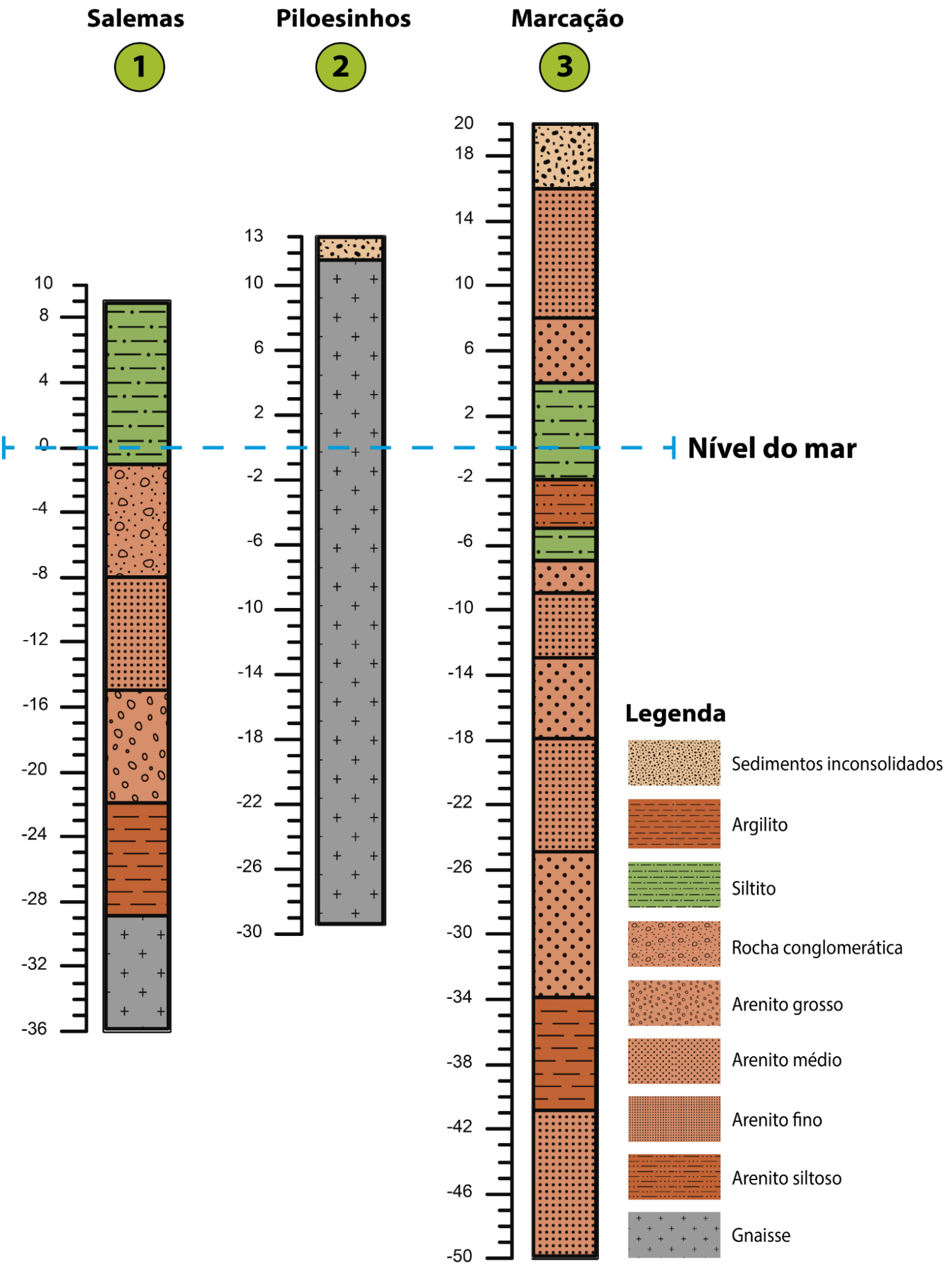

Figura 10 - Perfil litoestratigráfico dos poços localizados na Figura na Figura 9. Os perfis dos poços 1 e 2 demonstram a posição do embasamento entre a borda (Horst) do vale no qual o rio está encaixado, e o fundo do vale (graben). Os rejeitos são de pequena escala, e neste local não ocorrem depósitos do Cretáceo da porção basal da bacia. Sobre a área de embasamento elevado a norte existe uma sucessão espessa de depósitos siliciclásticos associados à Formação Barreiras. A boca dos poços está posicionada conforme sua elevação topográfica. 


\section{RECURSOS ECONÔMICOS}

$\mathrm{Na}$ região existem afloramentos de rochas graníticas da Suíte Intrusiva Ouro Branco, os quais são explotados pela atividade mineira na região (Fig. 11A). O aproveitamento se dá a partir da produção de blocos de paralelepípedos para pavimentação. $\mathrm{Na}$ cidade de Mamanguape também existe uma pedreira que estava desativada durante 0 período da pesquisa, destinada a este tipo de atividade. Também é comum a extração de material arenoso da Formação Barreiras que é destinado a aterros e pavimentação de estradas de terra na zona rural (Fig. 11B). Depósitos argilosos da Formação Barreiras também são utilizados para a fabricação de cerâmicas em olarias de pequeno porte. Os depósitos arenosos quartzosos são extraídos para a fabricação de vidros (Figs. 11C e 11D). A vasta cobertura proporcionada
pelos depósitos colúvio-eluviais favoreceu a formação de solos do tipo argissolo de coloração vermelhoamarelada e neossolos quartzarênicos, que são solos medianamente profundos, moderadamente drenados e com baixos teores de matéria orgânica (EMBRAPA, 1999). O cultivo de canade-açúcar é amplamente desenvolvido nas áreas elevadas formadas pelos depósitos da unidade Barreiras sobre as quais se desenvolveram esses solos.

Nos depósitos das unidades Barreiras e Pós-Barreiras também se desenvolveram aquíferos importantes nesta região (Dantas, 2012).

A pesquisa não conseguiu avaliar o potencial para o aproveitamento de ferro a partir dos depósitos de laterita que ocorrem na região. Entretanto, recomenda-se que mais pesquisas sejam desenvolvidas na área, em locais onde as coberturas Barreiras e PósBarreiras são espessas, e a quantidade de laterita pode ser expressiva (Fig. $11 \mathrm{E})$. 

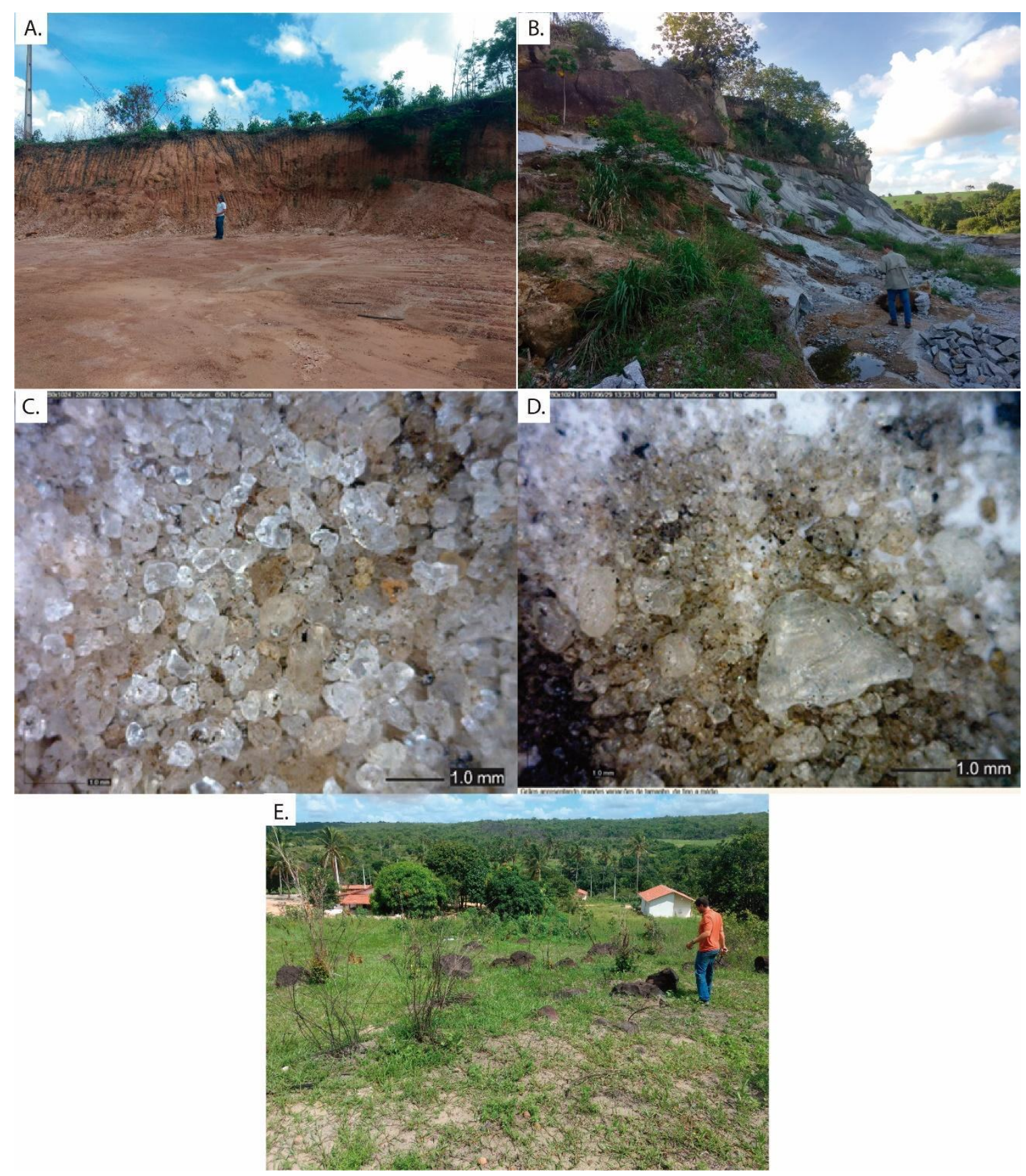

Figura 11 - Ocorrência de potencial econômico mineral. A) Extração de depósitos da unidade Barreiras na localidade de Praia de Campina, B) Mina que realiza extração de blocos de paralelepipedos em rochas da Suite Ouro Branco, na região de Mamanguape, $\mathrm{C}$ e D) Detalhe de sedimentos quartzosos encontrados nas coberturas elúvio-coluvionares, com granulação sub-angulosa a sub-arredondada, E) Ocorrência de blocos de material arenoso com cimentação de ferro, laterita, na localidade de Marcação.

\section{DISCUSSÃO DOS RESULTADOS}

A pesquisa comprovou que no trecho de faixa costeira estudado afloram apenas depósitos de idade Neógena-Quaternária (Fm. Barreiras).
É possível que conforme proposto por outros trabalhos existam depósitos do Cretáceo Superior na região do litoral (Barbosa et al, 2007), formações 
Itamaracá e Gramame. Entretanto, a cobertura de depósitos do Cenozóico, principalmente no vale do Rio Mamanguape, após os processos de erosão das regiões rebaixadas dos vales durante o Holoceno demonstra que estas unidades não afloram ou foram erodidas das porções proximais da faixa costeira.

O controle da tectônica recente, a partir da reativação transcorrente de estruturas do embasamento exerceu forte influência nos processos erosivos que atuam sobre a Formação Barreiras, este processo condicionou a orientação da drenagem e o rejuvenescimento dos vales dos estuários como observado no Rio Mamanguape (Figs. 4 e 9) (Bezerra et al., 2014; Lima et al., 2016). A observação dos depósitos que ocorrem em subsuperfície nos limites do vale do Rio Mamanguape, a partir de perfis de poços, demonstrou que na região proximal da faixa costeira o vale está implantado sobre depósitos Quaternários, e, possivelmente, depósitos da unidade Beberibe?. Nesta região proximal as unidades Cretáceas possivelmente foram erodidas a partir dos processos tectono-eustáticos do Pleistoceno e Holoceno. Além disso, a correlação dos perfis demonstra que o rejeito das falhas que limitam o graben, onde o vale deste rio está encaixado, é de apenas alguns metros. A sedimentação sobre os horsts relacionados a este vale na região proximal, também é dominada pela unidade Barreiras e depósitos do Holoceno (Fig. 10).

A ocorrência de camadas ou de blocos isolados de laterita é comum na área estudada. Em geral, os blocos resultam da erosão de paleo-horizontes de lateritização (Figs. 11E e 12). A gênese desses horizontes lateríticos é importante para se entender 0 desenvolvimento do relevo holocênico na região. Rossetti et al. $(2011,2013)$ propuseram a formação desses horizontes a partir dos processos de transgressão e regressão do nível do mar ocorrida entre o fim do Oligoceno e o início do Mioceno. Este fato permitiu o início da segunda fase de hiato deposicional e erosão subaérea que durou até o fim do Quaternário, o que influenciou a formação destes depósitos lateríticos. Parte desses horizontes lateríticos, resultantes da erosão, retrabalhamento, e cimentação dos depósitos da unidade Barreiras foram posteriormente recobertos por sedimentos denominados de PósBarreiras. Outra parte desses horizontes de alteração permaneceu exposta ou parcialmente aflorante em encostas conforme demonstrado na Figura 12B.

Dos Santos et al. (2018), sugeriram que as crostas lateríticas representam o produto da exposição da unidade Barreiras em um ambiente úmido que propiciou a formação de solos com teor de ferro suficiente para a formação desses horizontes. Este processo teve início com a formação de plintita, e envolveu vários ciclos de umedecimento e ressecamento acentuados, 0 que gerou a consolidação do material com a cimentação ferruginosa (petroplintita) caraterística desses horizontes. Este estudo observou que existe um controle topográfico na associação entre os horizontes lateríticos, expostos em algumas encostas e a formação dos blocos soltos de laterita devido a erosão. A ocorrência dos horizontes e dos blocos pode ser acompanhada a partir das cotas topográficas.

$\mathrm{Na}$ Figura 12B encontra-se um esquema onde é descrito o processo de erosão desses horizontes lateríticos, posicionados no topo da Formação Barreiras, e a formação dos blocos de laterita durante o Holoceno. 

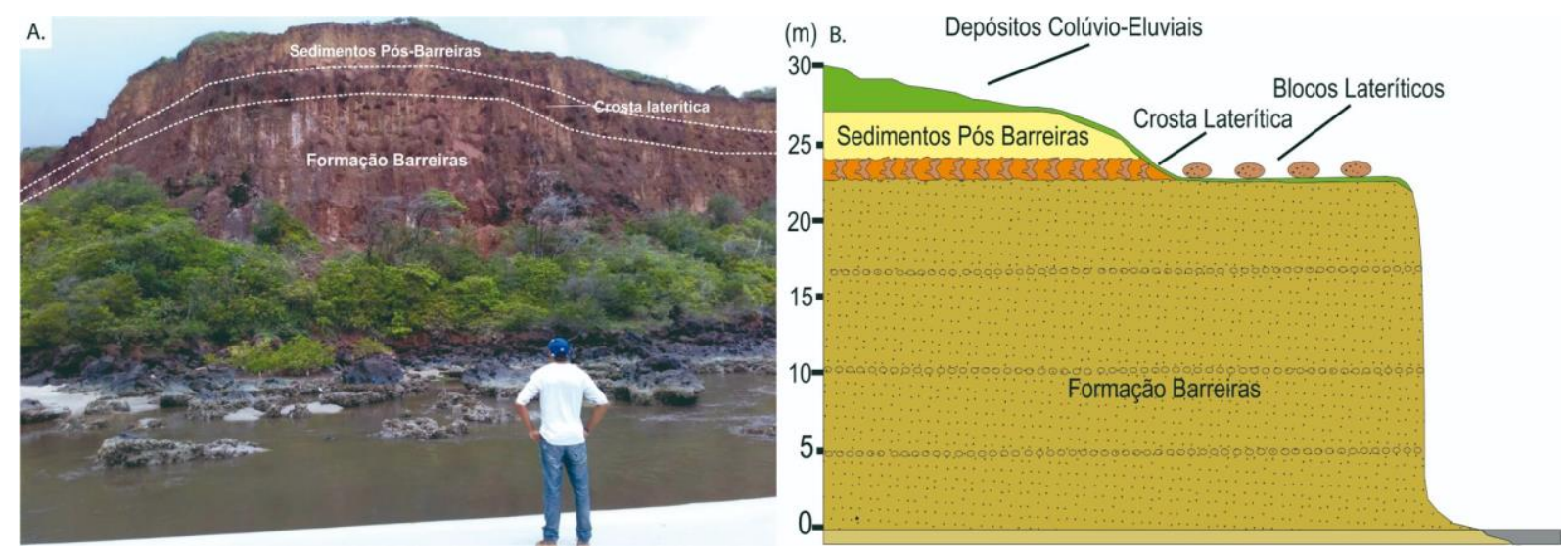

Figura 12: A) Perfil mostrando a relação da Formação Barreiras com os sedimentos Pós Barreiras. B) Perfil ilustrativo mostrando possível interpretação para relação entre a crosta laterítica e os blocos lateríticos.

\section{CONCLUSÕES}

O presente trabalho apresentou os resultados da investigação da geologia de superfície, integrada a informações de perfis de poços, de um trecho da faixa costeira da Bacia Paraíba com foco no vale do Rio Mamanguape, PB. Foi possível produzir um mapa geológico na escala de 1:50.000 nesta área que foi mapeada anteriormente nas cartas geológicas Cabedelo e Guarabira (1:100.000).

Oito unidades estratigráficas e litotipos sedimentares foram identificados na região. As formações Barreiras e Pós-Barreiras, terraços pleistocênicos, e coberturas de sedimentos holocênicos (sedimentos praiais, manguezais, aluviões, e coberturas eluvio-coluviais), além de rochas graníticas da suíte Ouro Branco. A unidade Barreiras aflora principalmente na região de litoral, onde a erosão produziu falésias. $\mathrm{Na}$ região dos vales dos rios e superfícies dos tabuleiros costeiros, formados por esta unidade, são encontrados depósitos eluviais e coluviais, produzidos pela erosão e lixiviamento das unidades Barreiras e PósBarreiras. O estudo dos modelos digitais de terreno, criados a partir de imagens de radar, permitiu a análise dos lineamentos topográficos e a correlação destes com estruturas do embasamento. Os lineamentos estão fortemente associados aos trends estruturais das zonas de cisalhamento do embasamento com direção ENEWSW, NE-SW, e falhas normais do rifte Cretácico, com direção N-S.

Depósitos da unidade PósBarreiras foram mapeados em algumas encostas de vales, e nestes a presença de blocos lateríticos oriundos da erosão do horizonte de alteração encontrado no topo da unidade Barreiras é frequente. A erosão deste horizonte laterítico deu origem a uma grande quantidade de blocos de tamanho centimétrico a métrico, encontrados em alguns locais da bacia. A ocorrência de blocos de material arenoso com forte cimentação ferruginosa tem origem na erosão e desagregação de camadas de natureza laterítica formadas pela exposição e intemperismo/ retrabalhamento dos depósitos da unidade Barreiras. A ocorrência destes horizontes lateríticos e dos blocos de arenito ferruginosos podem ser definidas a partir de cotas topográficas de controle.

A área de estudo apresenta alguns potenciais para aproveitamento de recursos minerais relacionados à 
agricultura, e materiais para a construção civil.

\section{REFERÊNCIAS}

Alheiros, M. M., Lima Filho, M. F. 1991. A Formação Barreiras. In: J.M. Mabesoone (Coord), Revisão geológica da Faixa Sedimentar Costeira de Pernambuco, Paraíba e Rio Grande do Norte. Estudos Geológicos, v. 10, p. 77-88.

Almeida, F. F. M., Hasui, Y., Brito Neves, B. B., Fuck, R. A. 1981. Brazilian structural provinces: an introduction. Earth-Science Reviews, 17(1-2), 1-29.

Alves, J. R. P. 2001. Manguezais: educar para proteger. Rio de Janeiro: Femar: Semads, 96.

Alves, F. C. 2016. Análise morfoestrutural das bacias dos rios Paraíba e Mamanguape (PB) com base em MDE-SRTM e imagem PALSAR/ALOS-1 (Doctoral dissertation, MSc Dissertation, Instituto Nacional de Pesquisas Espaciais, INPE, 151p. Alves, F. C., \& Rossetti, D. F. 2016. Influência neotectônica no estabelecimento dos vales dos rios Paraíba e Mamanguape, norte da bacia Paraíba (PB). Revista Brasileira de Geomorfologia, 17(3).

Andrades-Filho, C. O., Rossetti, D. F., Bezerra, F. H. R., Medeiros, W. E., Valeriano, M. M., Cremon, É. H., de Oliveira, R. G. 2014. Mapping Neogene and Quaternary sedimentary deposits in northeastern Brazil by integrating geophysics, remote sensing and geological field data. Journal of South American Earth Sciences, 56, 316-327.

Andrades-Filho, C. O., Rossetti, D. F., \& Bezerra, F. H. R. 2021. The unsteady post-rift stage of the South American passive margin based on the tectono-sedimentary evolution of the onshore Paraíba Basin, NE Brazil. Quaternary International, 580, 100-119.

Araújo, V. D., Reyes-Peres, Y. A., de Oliveira Lima, R., Pelosi, A. P. D. M. R., Menezes, L., Córdoba, V. C., Lima-Filho, F. P. 2006. Fácies e sistema deposicional da Formação Barreiras na região da Barreira do Inferno, litoral oriental do Rio Grande do Norte. Geologia USP. Série Científica, 6(2), 43-49.

Araújo, C. E. G., Cordani, U. G., Basei, M. A., Castro, N. A., Sato, K., Sproesser, W. M. 2012. U-Pb detrital zircon provenance of metasedimentary rocks from the Ceará Central and Médio Coreaú Domains, Borborema Province, NE-Brazil: tectonic implications for a long-lived Neoproterozoic active continental margin. Precambrian Research, 206, 36-51.

Barbosa, J.A. 2004. Evolução da Bacia da Paraíba durante o Maastrichtiano- Paleoceno: formações Gramame e Maria Farinha, NE do Brasil. Dissertação de mestrado, Pósgraduação em geociências UFPE. 230p.

Barbosa, J. A., Lima Filho, M. F. 2006. Aspectos estruturais e estratigráficos da faixa costeira Recife-Natal: observações em dados de poços. Boletim de Geociências da PETROBRAS, 14(1), 287-306.

Barbosa, J. A., Viana, M. S. S., Neumann, V. H. 2006. Paleoambientes e icnofáceis da seqüência carbonática da Bacia da Paraíba (CretáceoPaleogeno), Nordeste do Brasil. Revista Brasileira de Geociências, 36(3), 449-464.

Barbosa, J.A. 2007. A Deposição Carbonática na Faixa Costeira das Bacias da Paraíba e da 
Plataforma de Natal, NE do Brasil: Aspectos Estratigráficos, Geoquímicos e Paleontológicos. Tese de doutorado, Pósgraduação em geociências UFPE. $278 \mathrm{pp}$.

Barbosa, J. A., Neumann, V. H., Lima Filho, M., Souza, E. D., Moraes, M. D. 2007. Estratigrafia da faixa costeira Recife-Natal (Bacia da Paraíba e Plataforma de Natal), NE Brasil. Estudos geológicos, 17(2), 3-30.

Beurlen K. 1967a. Estratigrafia da faixa sedimentar costeira Recife-João Pessoa. Bol. Geol. São Paulo, SP. 16(1): 43-53.

Bezerra, F. H. R., Rossetti, D. F., Oliveira, R. G., Medeiros, W. E., Neves, B. B., Balsamo, F., Góes, A. M. 2014. Neotectonic reactivation of shear zones and implications for faulting style and geometry in the continental margin of NE Brazil. Tectonophysics, 614, 78-90.

Bezerra, F. H., de Castro, D. L., Maia, R. P., Sousa, M. O., Moura-Lima, E. N., Rossetti, D. F., Nogueira, F. C. 2020. Postrift stress field inversion in the Potiguar Basin, Brazil-Implications for petroleum systems and evolution of the equatorial margin of South America. Marine and Petroleum Geology, 111, 88-104.

Buarque, B. V., Barbosa, J. A., Magalhães, J. R., Oliveira, J. T. C., \& Correia Filho, O. J. 2016. Post-rift volcanic structures of the Pernambuco Plateau, northeastern Brazil. Journal of South American Earth Sciences, 70, 251-267.

Bueno, G. V. 2004. Diacronismo de eventos no rifte Sul-Atlântico. Boletim de Geociências da Petrobras, Rio de Janeiro, 12(2), 203-229.
Caixeta, J. M., Ferreira, T. S., Machado Jr, D. L., Teixeira, J. L., Marco, A. T., Romeiro, M. A. T. 2015. O desenvolvimento da margem rifteada vulcânica albiana no Nordeste brasileiro e seu perfil para a geração de petróleo. BG. Petrobras, Rio de Janeiro, 23(1/2).

Correia Filho, O. J., Alencar, M. L., Barbosa, J. A., Neumann, V. H. 2015. Proposta de formalização da formação Tambaba, Eoceno da bacia Paraíba, NE do Brasil. Estudos Geológicos, 25(2), 61-81.

Correia Filho, O. J., Barbosa, J. A., Tavares, B., da Silva, H. A., de Araujo Monteiro, K., Fabin, C. E. G., da Silva, S. M. 2019. Reativação Tectônica Quaternária no Domínio Sul da Província Borborema, NE do Brasil: Integração de Dados Morfométricos, Geológicos e Geofísicos da Bacia do Rio Una. Anuário do Instituto de Geociências, 42(4), 219-237.

Dantas, J. W. S. 2012. Caracterização hidrogeológica e critérios para construção de poços na Bacia Sedimentar Paraíba (Master's thesis, Universidade Federal de Pernambuco).

Delgado, I. D. M., Souza, J. D., Silva, L. D., Silveira Filho, N. D., Santos, R. D., Pedreira, A. J., Heineck, C. A. (2003). Geotectônica do escudo atlântico. Geologia, tectônica e recursos minerais do Brasil, 5, 227-334.

Dos Santos, H. G., Jacomine, P. K. T., Dos Anjos, L. H. C., De Oliveira, V. A., Lumbreras, J. F., Coelho, M. R., Cunha, T. J. F. 2018. Sistema brasileiro de classificação de solos. Brasília, DF: Embrapa.

EMBRAPA, Solos 1999. Sistema brasileiro de classificação de solos. EMBRAPA Produção de Informação, Brasília, p. 16. 
Ernesto, M., Marques, L. S., Piccirillo, E. M., Molina, E. C., Ussami, N., Comin-Chiaramonti, P., Bellieni, G. 2002. Paraná Magmatic Province-Tristan da Cunha plume system: fixed versus mobile plume, petrogenetic considerations and alternative heat sources. Journal of Volcanology and Geothermal Research, 118(1-2), 15-36.

Ernesto, M., Raposo, M. I. B., Marques, L. S., Renne, P. R., Diogo, L. A., De Min, A. 1999. Paleomagnetism, geochemistry and 40Ar/39Ar dating of the Northeastern Paraná Magmatic Province: tectonic implications. Journal of Geodynamics, 28(4-5), 321-340.

Fauth, G., Koutsoukos, E. A. M. 2002. Paleoecological inferences from marine ostracode assemblage of the Maastrichtian and Danian in the Pernambuco-Paraíba Basin. Simpósio sobre o Cretáceo do Brasil, 4, 261-265.

Furrier, M., de Araújo, M. E., \& de Meneses, L. F. 2006. Geomorfologia e tectônica da Formação Barreiras no Estado da Paraíba. Geologia USP. Série Científica, 6(2), 61-70.

Kegel, W. 1955. Geologia do fosfato de Pernambuco. Ministério da Agricultura, DNPM.

Lima, C. C. U. 2010. Evidências da ação tectônica nos sedimentos da Formação Barreiras presentes do litoral de Sergipe e ao norte da Bahia. Revista de Geografia (Recife), 27(1. Esp), 140-151.

Lima, J. C., Bezerra, F. H., Rossetti, D. F., Barbosa, J. A., Medeiros, W. E., de Castro, D. L., Vasconcelos, D. L. 2017. Neogene-Quaternary fault reactivation influences coastal basin sedimentation and landform in the continental margin of NE Brazil. Quaternary International, 438, 92-107.

Mabesoone, J. M.; Alheiros, M. M. 1988. Origem da bacia sedimentar costeira PernambucoParaíba. Revista Brasileira de Geociências, v. 18, n. 4, p. 476482.

Mabesoone, J. M. \& Alheiros, M. M. 1993. Evolution of the Pernambuco-Paraíba- Rio Grande do Norte Basin and the problem of the South Atlantic connection. Geologie en Mijnbouw, 71: 351-362

Magalhães, J. R. G., Oliveira, J. T. C., Barbosa, J. A., de Lima Filho, M. 2013. Continental Oceanic Crustal Transition In The Paraíba Basin Platform, Northeast Brazil Transição da Crosta Continentaloceânica Na Plataforma da Bacia da Paraíba, NE Do Brazil. Estudos Geológicos, 23, 2.

Matos, R. M. D. 1999. History of the northeast Brazilian rift system: kinematic implications for the break-up between Brazil and West Africa. Geological Society, London, Special Publications, 153(1), 55-73.

Matos, R. M. D., Krueger, A., Norton, I., Casey, K. 2021. The fundamental role of the Borborema and BeninNigeria provinces of NE Brazil and NW Africa during the development of the South Atlantic Cretaceous Rift system. Marine and Petroleum Geology, 127, 104872. Mincato, R. L., Enzweiler, J., \& Schrank, A. 2003. Novas idades 39Ar/40Ar e implicações na metalogênese dos depósitos de sulfetos magmáticos de $\mathrm{Ni}-\mathrm{Cu}$ EPG na Província Ígnea Continental do Paraná. In 9th Brazilian Congress of Geochemistry, Belém (Pará), Brazil. pp. 2-9. 
Muniz, G. C. B. 1993. Novos moluscos da Formação Gramame, Cretáceo Superior dos Estados da Paraíba e de Pernambuco, Nordeste do Brasil. Departamento de Geologia, Universidade Federal de Pernambuco. Publicação Especial 1, $202 p$.

Neumann, V. H. D. M. L., Guerra, N. C. 2014. Folha Cabedelo, SB. 25YA-VI. CPRM

Neves, B. B. B., Van Schmus, W. R., Fetter, A. H. 2001. Noroeste da África-Nordeste do Brasil (Província Borborema) ensaio comparativo e problemas de correlação. Geologia USP. Série Científica, 1, 59-78.

Rand, H. M. 1976. Estudos geofísicos na faixa litorânea ao sul do Recife. Universidade Federal de Pernambuco, Recife. Tese de Doutorado. Tese de Livre Docência, 112p.

Renne, P. R., Ernesto, M., Pacca, I. G., Coe, R. S., Glen, J. M., Prévot, M., Perrin, M. 1992. The age of Paraná flood volcanism, rifting of Gondwanaland, and the JurassicCretaceous boundary. Science, 258(5084), 975-979.

Rossetti, D. F., Bezerra, F. H. R., Góes, A. M., Valeriano, M. M., Andrades Filho, C. O., Mittani, J. C. R., Brito Neves, B. B. 2011. Late Quaternary sedimentation in the Paraíba Basin, northeastern Brazil: implications for the interplay among landform, sea level and tectonics in Eastern South America passive margin. Palaeogeography,

Palaeoclimatology,

Palaeoecology, 300(1-4), 191204.

Rossetti, D. F., Bezerra, F. H., Dominguez, J. M. 2013. Late Oligocene-Miocene

transgressions along the equatorial and eastern margins of
Brazil. Earth-Science Reviews, 123, 87-112.

Santos, E. D. 1996. Ensaio preliminar sobre terrenos e tectônica acrescionária na Província Borborema. In Congresso Brasileiro de Geologia. V. 39, pp. 47-50. SBG Salvador.

Santos, E. J. D., Ferreira, C. A. 2002. Geologia e recursos minerais do Estado da Paraíba. CPRM.

Santos, L. C. M. L. 2010. Mapeamento Geológico e Análise Litoestratigráfica do Precambriano da Região de Sucuru (Paraíba), Terreno Alto Moxotó, Província Borborema. Relatório de graduação. Departamento de Geologia, Universidade Federal de Pernambuco-Recife-PE.

Suguio, K., Angulo, R. J., Carvalho, A. M., Corrêa, I. C., Tomazelli, L. J., Willwock, J. A., Vital, H. 2005. Paleoníveis do mar e paleolinhas de costa. Quaternário do Brasil, 114-129.

Suguio, K. (2017). Geologia do Quaternário e mudanças ambientais. Oficina de textos.408p.

Streckeisen, A. 1976. To each plutonic rock its proper name. EarthScience Reviews, 12(1), 1-33.

Suguio, K., Sallun, A. E. M., Soares, E. A. A. 2005. Período Quaternário: "Quo Vadis"?. Revista Brasileira de Geociências, 35(3), 427-432.

Távora, V. D. A., Dias, J. J., Correia Filho, O. J., Barbosa, J. A. 2019. Petrografia dos Calcários Recifais da Formação Tambaba (Eoceno), Bacia da Paraíba, Brasil. Anuário do Instituto de Geociências, 40(3), 341-358.

Turner, S., Regelous, M., Kelley, S., Hawkesworth, C., Mantovani, M. 1994. Magmatism and continental break-up in the South Atlantic: high precision 40Ar-39Ar geochronology. Earth and 
Planetary Science Letters, 121(34), 333-348.

Wentworth, C. K. 1922. A scale of grade and class terms for clastic sediments. The Journal of Geology, 30(5), 377-392. 